\title{
The Prevalence of Peripheral Arterial Disease in HIV Patients
}

Nishant Gupta1, Sharad Bajaj ${ }^{1}$, Priyank Shah ${ }^{2 *}$, Rupen Parikh${ }^{1}$, Isha Gupta ${ }^{2}$, Wishwdeep Dhillon², Vincent Debari ${ }^{3}$, Aiman Hamdan¹, Fayez Shamoon $^{4}$, Michael Lange ${ }^{5}$ and Mahesh Bikkina ${ }^{1}$

${ }^{1}$ Department of Cardiology, St. Joseph's Regional Medical Center, 703 Main St., Paterson NJ 07503, USA

${ }^{2}$ Department of Internal Medicine, St. Joseph's Regional Medical Center, 703 Main St., Paterson NJ 07503, USA

${ }^{3}$ Department of Internal Medicine, School of Health and Medical Sciences, Seton Hall University, 400 South Orange Ave, South Orange NJ 07079, USA

${ }^{4}$ Department of Cardiology, St. Michael's Medical Center, 111 Central Ave, Newark NJ 07102, USA

${ }^{5}$ Department of Infectious Disease, St. Joseph's Regional Medical Center, 703 Main St., Paterson NJ 07503, USA

\section{Abstract}

Background: The actual prevalence of Peripheral Arterial Disease (PAD) in Human Immunodeficiency Virus (HIV) infected patients is still unknown.

Aim: The aim of our study was to assess the prevalence of PAD using Ankle Brachial Index (ABI) (both rest and exercise) measurement in HIV infected patients with head-to-head comparison with the sex-matched non-HIV controls.

Methods: We randomly enrolled total of 214 patients (70 HIV patients and 144 non-HIV controls), from March 2009 to December 2009. The Edinburg Claudication Questionnaire and ABI were used as study tools. Normal ABI was defined as 0.9 to 1.3. Data was analyzed using the Fischer's Exact Test. Various cardiovascular and infectious risk factors for PAD were also analyzed.

Results: Claudication was reported using Edinburgh questionnaire in 28.5\% HIV patients as compared to 12.5 $\%$ patients in non-HIV group ( $p$ value 0.0069 ). Abnormal ABI suggestive of PAD i.e. ABI $<0.9$ or $>15 \%$ absolute drop on exercise was reported in $10 \%$ HIV patients as compared to $1.3 \%$ in non-HIV group (p value 0.006 ). Based on multivariate analysis, age, Caucasian race, hypertension, diabetes mellitus, hyperlipidemia, metabolic syndrome and low CD4 count were found to be independent predictors of PAD.

Conclusions: The prevalence of PAD is higher in HIV patients as compared to sex-matched non-HIV controls. Hence, HIV patients should be routinely screened for PAD using rest and exercise ABI. Apart from correlation with cardiovascular risk factors, strong association between lower CD4 cell count and abnormal ABI exists. This warrants more aggressive approach in managing cardiovascular and infectious markers in HIV patients with abnormal $A B I$.

Keywords: Peripheral arterial disease; Ankle brachial index; HIV; Prevalence

\section{Background}

The life expectancy in Human Immunodeficiency Virus (HIV) infected patients is increased after the introduction of Highly Active Antiretroviral Therapy (HAART). However, there is a growing concern of cardiovascular disease, in general and peripheral arterial disease (PAD), in particular in this population [1-3]. A variety of atherogenic metabolic abnormalities including dyslipidemia, lipodystrophy and insulin resistance have been reported after the use of protease inhibitors (PI) [4,5]. Moreover, HIV causes direct injury to the arterial wall resulting in inflammation and atherosclerosis [6,7]. This has led to the greater interest in detection of atherosclerosis by measuring carotid intimal thickening, endothelial dysfunction and coronary calcification [8-10].

PAD is a focal manifestation of atherosclerosis and is a predictor of cardiovascular outcomes [11]. In the majority of cases, patients with PAD remain asymptomatic. Therefore, early diagnosis of PAD may provide an opportunity for physicians to identify and prevent cardiovascular events in high-risk patients.

The actual prevalence of PAD in HIV patients is still unknown. Various studies have reported the prevalence in HIV patients ranging from $0.9 \%$ to around $30 \%$ [12-18]. This can be partly explained by heterogeneous selection of patients, gender-specific variations and the lack of high volume non-HIV control population group [19]. The primary objective of our study was to assess the prevalence of PAD using Ankle Brachial Index (ABI) (both rest and exercise) measurement in HIV patients with head-to-head comparison with the sex-matched non-HIV control group.

\section{Methods}

\section{Study setting}

This study was conducted at a 700-bed tertiary care teaching hospital in Northern New Jersey, USA. The protocol was approved by the Institution Review Board (St. Joseph's Health Care System IRB). All the participants provided written informed consent and rationale for the study was explained.

\section{Study design and subjects}

We enrolled total of 214 consecutive patients (70 in HIV group and 144 as non-HIV controls) from March, 2009 to December, 2009. The study group comprised $70 \mathrm{HIV}$-infected patients, who were seen

*Corresponding author: Priyank Shah, 249 Belleville Avenue, Apt. 21-B, Bloomfield NJ 07003, USA, Tel: 8625914954; E-mail: priyank_221084@yahoo.com

Received September 20, 2013; Accepted October 26, 2013; Published October 28, 2013

Citation: Gupta N, Bajaj S, Shah P, Parikh R, Gupta I, et al. (2013) The Prevalence of Peripheral Arterial Disease in HIV Patients. J Vasc Med Surg 1: 118 doi: 10.4172/2329-6925.1000118

Copyright: ( 2013 Gupta N, et al. This is an open-access article distributed unde the terms of the Creative Commons Attribution License, which permits unrestricted use, distribution, and reproduction in any medium, provided the original author and source are credited. 
in HIV Comprehensive Care Clinic or were admitted in St. Joseph's Regional Medical Center, New Jersey. The patients were excluded if they were active intravenous drug abusers, $<40$ years of age or if they were previously diagnosed with PAD (confirmed by arteriography or vascular Doppler ultrasound). Symptoms potentially related to PAD (claudication, rest pain, and non healing leg wounds) were recorded using the Edinburgh Claudication Questionnaire [20]. The patient distribution is further elaborated in Figure 1.

The comparison was done with sex-matched non-HIV controls $(\mathrm{n}=144)$ from the same population group. In addition, various infectious disease parameters such as mode of HIV transmission, CD4 count, HIV viral load, duration of seropositivity (since diagnosis, in years), Exposure to Protease Inhibitors (PI) were compared among HIV population who had $\mathrm{ABI}<0.9 \mathrm{Vs} \mathrm{ABI} \geq 0.9$.

ABI was obtained using a high sensitivity $8-\mathrm{MHz}$ Doppler ultrasound probe and a sphygmomanometer with appropriate bloodpressure cuff size by a single certified experienced vascular laboratory technician. The patient would lie in a supine position for at least $5 \mathrm{~min}$ prior to blood pressure measurements. The higher of the two blood pressure readings measured in the lower extremities (dorsalis pedis or posterior tibial) and the higher of the two brachial pressures were used to calculate the $\mathrm{ABI}$ for each lower limb and the lower of the two $\mathrm{ABI}$ readings was recorded as the patient's overall resting $A B I$. Exercise $A B I$ was defined as ABI measured after performing 20 squats slowly under supervision [21]. Squatting was used because of its simplicity and it does not require a treadmill in the clinical settings.

\section{Peripheral arterial disease definition}

Based on American Heart Association and American College of Cardiology guidelines, abnormal ABI suggestive of PAD was defined as $\mathrm{ABI}<0.9$ or if there was absolute decrease of $>0.15$ on exercise [21,22]. Total abnormal ABI was calculated by adding ABI $>1.3$ to the abnormal ABI. Different studies have used different thresholds to define exercise related decrease in ABI [12]. As all the measurements were performed by the same observer, we kept the absolute decrease of $>0.15$ as abnormal.

\section{Clinical Characteristics and Infectious Disease Parameters}

Data on various baseline clinical characteristics were obtained from patients and the institutional electronic database. These characteristics

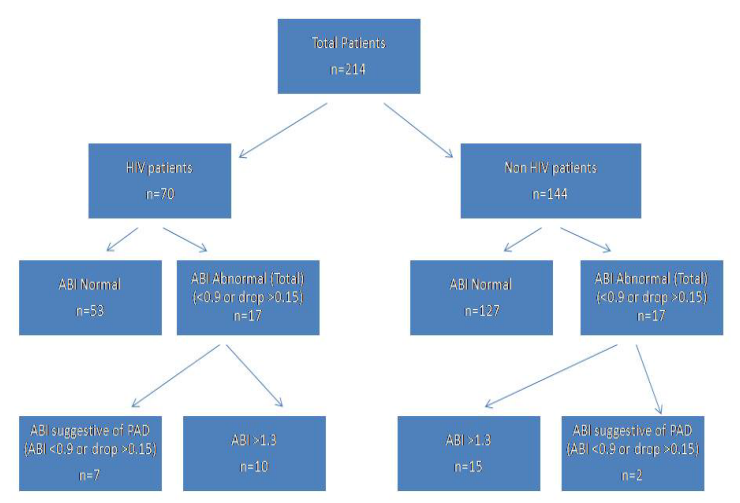

Figure 1: Patient Distribution and Study Methodology.

This figure depicts distribution of HIV and non-HIV patients with normal and abnormal $\mathrm{ABI}$. ABI - Ankle Brachial Index; PAD -Peripheral Arterial Disease. included: age, gender, ethnicity/Race, previous history of hypertension (defined as brachial blood pressure of $>140 / 90 \mathrm{mmHg}$, as measured after 5 minutes of rest or being on any antihypertensive drugs), previous history of diabetes mellitus (defined as either a self reported diagnosis or treatment with medications), previous history of dyslipidemia (defined as high density lipoprotein (HDL) $\leq 1.03 \mathrm{mmol} / \mathrm{l}$, Non-HDL cholesterol $\geq 4.91 \mathrm{mmol} / \mathrm{l}$, triglycerides $\geq 2.25 \mathrm{mmol} / \mathrm{l}$ or on current treatment) [23], family history of cardiovascular disease, active smoking and the presence of metabolic syndrome (based on International Diabetes Federation Criteria) [24] (Table 1). Cutoff values were determined by receiver-operating characteristic (ROC) curve analysis. For example, the cutoff values for the age as $53, \mathrm{CD} 4$ count as 250 cells/microlitre and HIV Viral load as 1500 IU/L were based on ROC curve analysis (Table 1 and 2). Following infectious disease parameters were collected: Mode of HIV transmission, CD4 count, HIV viral load, duration of seropositivity, and exposure to Protease Inhibitors (PI).

\section{Statistical Analysis}

The association between two groups of categorical variables was reviewed by $2 \times 2$ contingency tables and analyzed by Fischer's exact test with two-sided $\mathrm{p}$-values $<0.05$ being considered statistically significant. Relative Risk (RR) and 95\% confidence intervals were similarly calculated. Baseline characteristic differences for which p-values were $<0.25$ were added to a multivariate logistic regression model and adjusted odds ratio and p-values were computed. Univariate calculations were performed using Prism software (Graph Pad Cap, San Diego, CA, USA). Multivariate logistic regression was performed using Web-based routine software (www.statpages.org/logistic; Last accessed $1 / 15 / 2011)$

\section{Results}

Out of a total of 214 patients, $70 \mathrm{HIV}$-infected patients and 144 non-HIV patients from the general population were evaluated for the prevalence of PAD. Claudication was reported using Edinburgh questionnaire in $28.5 \%(\mathrm{n}=20) \mathrm{HIV}$-infected patients as compared to $12.5 \%(\mathrm{n}=18)$ patients in non-HIV group ( $\mathrm{p}$ value 0.0069$)$. Abnormal $\mathrm{ABI}$ suggestive of $\mathrm{PAD}$ i.e. $\mathrm{ABI}<0.9$ or $>0.15$ absolute drop on exercise was reported in $10 \%(\mathrm{n}=7) \mathrm{HIV}$-infected patients as compared to $1.3 \%$ $(n=2)$ in non-HIV group ( $p$ value 0.006 ) (Figure 2 ). The results remained statistically significant after adjusting for other risk factors for PAD. We found a trend towards higher (statistically non-significant) prevalence of high $\mathrm{ABI}>1.3$ in HIV population when compared to non-HIV group (14.2\% Vs 10.4\%). Total Abnormal ABI (Abnormal ABI+ABI >1.3) was recorded in $24.3 \%(n=17)$ HIV-infected patients versus $11.8 \%(n=17)$ non-HIV patients (p value 0.02) (Figure 3).

All the patients were appropriately sex-matched among both groups. The comparison of clinical characteristics demonstrated that there were statistically higher number of patients with Caucasian race, hypertension, diabetes mellitus and low HDL in non-HIV group when compared to HIV group. In contrast, there were more patients with younger age and metabolic syndrome in HIV group as compared to non-HIV patients (Table 1). Based on multivariate logistic regression analysis of the clinical characteristics, age, Caucasian race, hypertension, diabetes mellitus, hyperlipidemia (Non-HDL Cholesterol $\geq 190$, HDL $\leq$ 40 , Triglycerides $\geq 200$ ) and metabolic syndrome were found to be independent predictors of PAD (Figure 4).

The comparison of Infectious Disease markers among the HIVinfected patients with $\mathrm{ABI}<0.9$ compared to $\geq 0.9$ showed that low CD 4 count $(\mathrm{CD} 4<250$ cells/microlitre) was an independent predictor 
Citation: Gupta N, Bajaj S, Shah P, Parikh R, Gupta I, et al. (2013) The Prevalence of Peripheral Arterial Disease in HIV Patients. J Vasc Med Surg 1: 118 doi: $10.4172 / 2329-6925.1000118$

Page 3 of 5

of PAD. Although, there was a trend towards high viral load among patients with PAD, but it did not reach statistical significance (Table 2). Also, no difference was noticed among both groups in terms of exposure to protease inhibitors (PI), duration of exposure to PIs or mode of HIV transmission.

\section{Discussion}

We found that the prevalence of PAD is significantly higher in HIV population as compared to sex matched controls based on the abnormal ABI (10\% Vs 1.3\%; p Value 0.006) and the Claudication Questionaire (28.5\% Vs 12.5\%; p Value 0.0069). We also noticed that the age, Caucasian race, hypertension, diabetes mellitus, Non-HDL Cholesterol $\geq 4.91 \mathrm{mmol} / \mathrm{l}, \mathrm{HDL} \leq 1.03 \mathrm{mmol} / \mathrm{l}$, Triglycerides $\geq 2.25$

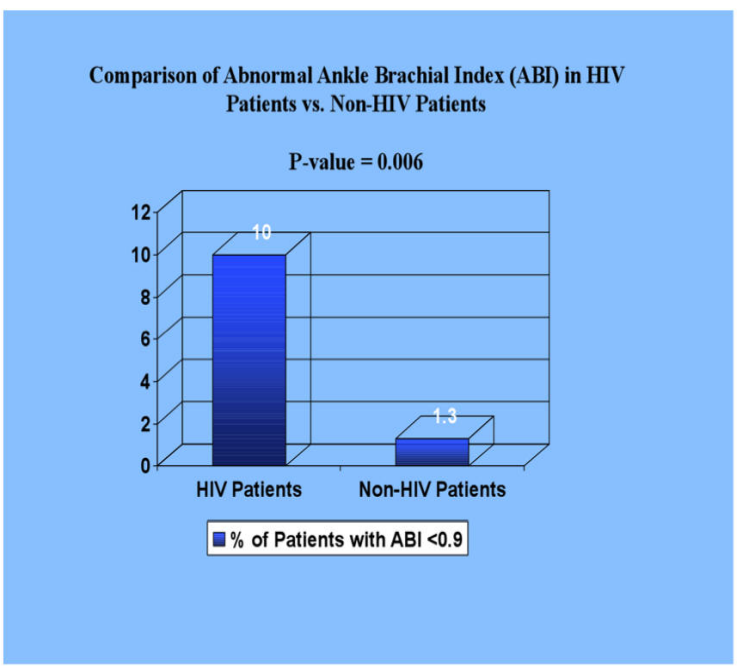

Figure 2: Comparison of Abnormal $\mathrm{ABI}$ in HIV vs. non-HIV patients. This figure shows percentage of abnormal $A B I(<0.9)$ in HIV and non-HIV patients. $\mathrm{ABI}$ - Ankle Brachial Index.

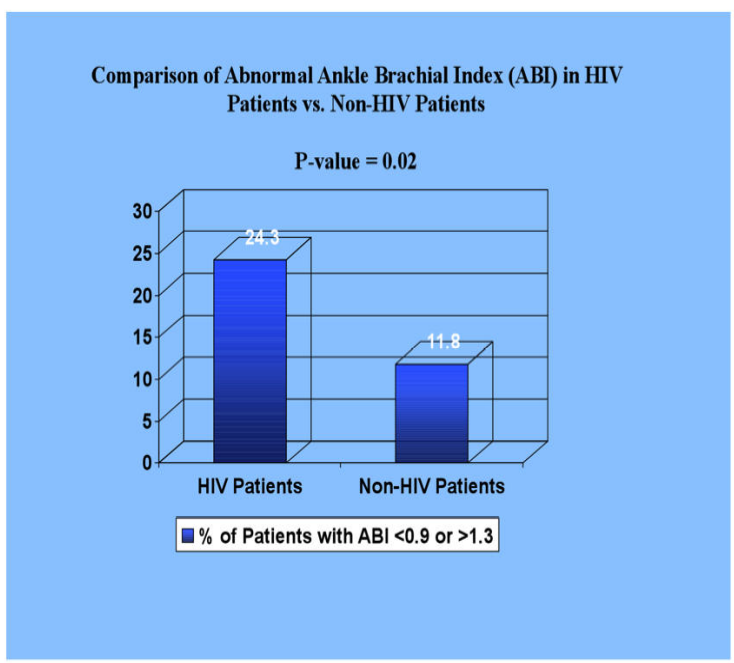

Figure 3: Comparison of Total abnormal $A B I$ in HIV vs. non-HIV patients. This figure shows percentage of total abnormal $\mathrm{ABI}(<0.9$ plus $>1.3)$ in HIV and non-HIV patients. $\mathrm{ABI}$ - Ankle Brachial Index.

\begin{tabular}{|c|c|c|c|}
\hline Characteristics & HIV & Non-HIV & P Value \\
\hline Gender & $n=70$ & $n=144$ & \\
\hline Male & $41(58.6 \%)$ & $77(53.5 \%)$ & 0.56 \\
\hline Female & $29(41.4 \%)$ & $67(46.5 \%)$ & \\
\hline \multicolumn{4}{|l|}{ Age(years) } \\
\hline Mean & 52 & 55 & \\
\hline$<53$ & $38(54.3 \%)$ & $58(40.3 \%)$ & 0.058 \\
\hline$\geq 53$ & $32(45.7 \%)$ & $86(59.7 \%)$ & \\
\hline \multicolumn{4}{|l|}{ Ethnicity/Race } \\
\hline Caucasian & $9(12.9 \%)$ & $44(30.6 \%)$ & 0.006 \\
\hline Hispanic & $29(41.4 \%)$ & $48(33.3 \%)$ & 0.288 \\
\hline African American & $32(45.7 \%)$ & $52(36.1 \%)$ & 0.18 \\
\hline \multicolumn{4}{|l|}{ Risk Factors } \\
\hline Family History of CVD† & $22(31.4 \%)$ & $55(38.2 \%)$ & 0.36 \\
\hline Hypertension & $27(38.6 \%)$ & $96(66.7 \%)$ & 0.001 \\
\hline Diabetes Mellitus & $14(20.0 \%)$ & $62(43.1 \%)$ & 0.0008 \\
\hline $\begin{array}{l}\text { Non-HDL } \\
\text { Cholesterol } \geq 4.91 \mathrm{mmol} / /\end{array}$ & $9(12.9 \%)$ & $29(20.1 \%)$ & 0.25 \\
\hline $\mathrm{HDL} \leq 1.03 \mathrm{mmol} / \mathrm{I}$ & $20(28.6 \%)$ & $66(45.8 \%)$ & 0.02 \\
\hline Triglycerides $\geq 2.25 \mathrm{mmol} / \mathrm{l}$ & $11(15.7 \%)$ & $13(9.0 \%)$ & 0.17 \\
\hline Smoking & $26(37.1 \%)$ & $44(30.6 \%)$ & 0.35 \\
\hline Metabolic Syndrome & $9(12.9 \%)$ & $6(4.2 \%)$ & 0.04 \\
\hline
\end{tabular}

† Cardiovascular Disease; †High Density Lipoprotein

Table 1: Comparison of the baseline characteristics of HIV Patients Vs. Non-HIV Patients.

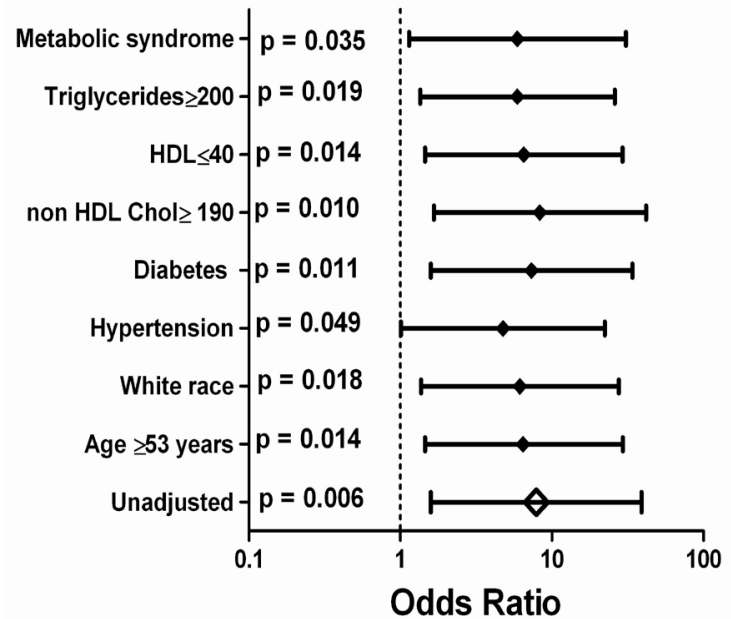

Figure 4: Odds of PAD in HIV patients after multivariate logistic regression. This figure forest plot graph indicating odds of Peripheral Arterial Disease in HIV patients after multivariate regression analysis for various risk factors. HDL - High Density Lipoprotein

\begin{tabular}{|c|c|c|c|c|}
\hline ID Markers & $\begin{array}{c}A B \mid<0.9 \\
(n=7)\end{array}$ & $\begin{array}{c}A B I \geq 0.9 \\
(n=63)\end{array}$ & $\begin{array}{c}\mathbf{P} \\
\text { Value }\end{array}$ & $\mathrm{RR}(95 \% \mathrm{Cl})$ \\
\hline \multicolumn{5}{|l|}{ Mode of Transmission } \\
\hline Heterosexual Sex & 4 & 32 & 1 & $1.259(0.30-5.22)$ \\
\hline IVDA & 1 & 10 & 1 & $0.89(0.11-6.7)$ \\
\hline Homosexual Sex & 1 & 13 & 1 & $0.66(0.087-5.1)$ \\
\hline Others* & 1 & 8 & 1 & $1.13(0.15-8.33)$ \\
\hline $\begin{array}{l}\text { CD4 count }<250 \text { cells/ } \\
\text { microlitre }\end{array}$ & 6 & 13 & 0.0012 & $16.11(2.071-125.2)$ \\
\hline HIV Viral load >1500 IU/L & 5 & 20 & 0.08 & $4.5(0.94-21.54)$ \\
\hline Exposure to Pls & 6 & 53 & 1 & $1.11(0.14-8.4)$ \\
\hline Duration of Seropositivity & $5.5 \pm 2.98$ & $5.9 \pm 3.9$ & 0.79 & $(-3.44-2.64)$ \\
\hline \multicolumn{5}{|c|}{$\begin{array}{l}\text { since diagnosis of HIV Infection.(In years)(Mean } \pm \text { SD) } \\
\text { ABI: Ankle Brachial Index; PI: Protease Inhibitors; IVDA: Intravenous Drug } \\
\text { Abusers; SD: Standard Deviation } \\
{ }^{*} \text { Needle Stick, Blood Transfusion, Transplacental etc. }\end{array}$} \\
\hline
\end{tabular}

Table 2: Comparison of Infectious disease (ID) markers between HIV patients with $\mathrm{ABI}<0.9 \mathrm{Vs}$. $\mathrm{ABI} \geq 0.9$

mmol/l, metabolic syndrome and low CD4 counts were identified as independent predictors of PAD in HIV-infected patients.

Analysis of different series report marked variation in the prevalence 
among HIV-infected patients in the literature [12-18]. Periard et al. [12] reported the prevalence of PAD in HIV-infected patients as $20.7 \%(9.8 \%$ with $\mathrm{ABI}<0.9$ at rest and $10.9 \%$ with $>25 \%$ decrease with exercise). On the contrary, Sharma et al reported the prevalence in HIV infected women as only $0.9 \%$ [15]. This variation in the prevalence is possibly related to lack of high volume sex-matched controls. The former did not compare the prevalence with high volume non-HIV controls and the latter had only selected women population for comparison. In our study, we report the prevalence in high volume sex-matched controls.

Although, Palacios et al. [13] and Sharma et al. [15] reported the prevalence in both HIV and non-HIV patients, they were in different patient groups. Sharma reported it in women population only with an average age of less than 40 years and Palacios used population mainly comprising of male patients ( $82.8 \%$ males). In the present study, we report the prevalence in more homogenously comparable gender groups. The mean age in HIV-infected patients was 52 years with $58.6 \%$ male patients as compared to mean age of 55 years with $53.5 \%$ males in non-HIV group.

In the recent times, post exercise $\mathrm{ABI}$ in HIV-infected patients is gaining attention as it has been reported that milder form of PAD can be missed by measuring resting ABI alone [25]. In this study, we have reported the changes in post exercise ABI consistent with PAD (drop of $>0.15$ ) in $4.3 \%$ patients. Periard et al. [12] and Qaqa et al. [18] reported similar findings in HIV-infected patients, $10.9 \%$ and $26.5 \%$ respectively. Although, Periard et al. [12] used the same post exercise criteria, the variation in our study compared to Qaqa et al. [18] is partly because of the use of different post exercise criteria to diagnose PAD (treadmill or pedal planter flexion test). Also, both Periard et al. [12] and Qaqa et al. [18] had higher number of males ( $76.1 \%$ and $83 \%$ respectively). The variation of greater than $15 \%$ in the reported literature (10.9\% Vs $26.5 \%)$ suggests the need for high volume control population for comparison. Despite the fact that we had lower number of HIV-infected patients in our study, the higher volume of sex matched controls, a single vascular specialist to perform all the ABI measurements and proportionate number of male population in both the groups set us apart from prior studies.

The prevalence of PAD in general population has been reported as $1 \%$ at 50 years and $3 \%$ at 60 years of age $[26,27]$. In our data, the prevalence reported in the non-HIV patients is $1.3 \%$ at mean age of 55 years. This result matches with the reported prevalence of 1-3\% from 50-60 years of age in the literature.

Despite the fact that the prevalence of $\mathrm{ABI}<0.9$ is higher in $\mathrm{HIV}$ infected persons than among the general population, high $\mathrm{ABI}$ is also more prevalent. There has been reported association of greater mortality (both total and cardiovascular) with $\mathrm{ABI} \geq 1.4$ [28]. However, clinical practice guidelines still retain the cut-off point for abnormal high $\mathrm{ABI}$ as $\geq 1.3$ [22].

We found a trend towards higher (statistically non-significant) prevalence of high $\mathrm{ABI} \geq 1.3$ in HIV population as compared to nonHIV group (14.2\% Vs 10.4\%). So far, only Sharma et al. [15] and Olalla et al. [17] have reported the prevalence of high ABI. Our study results match with Sharma et al in reporting the similar prevalence of high ABI $(\mathrm{ABI} \geq 1.4)$ in HIV infected Vs uninfected patients (7.2\% Vs 6.3\%). The higher percentage found in our patients can be explained because of the use of cut-off for high ABI as $\geq 1.3$ and by inclusion of patients of both sex. Olalla et al. also reported the prevalence of $A B I \geq 1.3$ as $19.7 \%$. This difference compared to our results can be partly explained by higher number of males (82\%) and smokers (59\%) in their patients [19].
Various studies have suggested a possible association between higher degree of immunosuppression and abnormal ABI [12,16,17]. Periad et al. [12] found that CD4 cell count below 200 cells per microlitre was a strong predictor of low ABI ( $p$ value 0.006 ). Similarly, Gutierrez et al. [16] and Olalla et al. [17] also found significant difference in CD4 cells in patients with abnormal ABI. In the present study, we found strong association between lower CD 4 cell count (CD4<250 cells/ microlitre) and abnormal ABI (p value 0.0012) (Table 2). Although, the association between high viral load and abnormal ABI could not reach statistical significance, there was a trend towards this association. These associations were found to be independent of PI use, indicating vascular damage by HIV independent of HAART.

In spite of having a lower number of patients with traditional cardiovascular risk factors like hypertension, diabetes mellitus and family history of cardiovascular disease in our HIV group, there was a higher prevalence of PAD as compared to non-HIV patients. This supports the fact that HIV infection itself plays a major and independent role in atherosclerotic process [29]. Based on the multivariate analysis of various cardiovascular risk factors associated with abnormal ABI, we found that age, Caucasian race, hypertension, diabetes mellitus, NonHDL Cholesterol $\geq 4.91 \mathrm{mmol} / \mathrm{l}, \mathrm{HDL} \leq 1.03 \mathrm{mmol} / \mathrm{l}$, Triglycerides $\geq$ $2.25 \mathrm{mmol} / \mathrm{l}$, metabolic syndrome were independent predictors of PAD.

An abnormal $\mathrm{ABI}$ is a marker of high vascular mortality and has been associated with lower 5-year survival rate. Therefore, it is very essential to identify patients with abnormal $\mathrm{ABI}$ to aggressively manage them to prolong survival [30]. As mentioned previously, ABI measurements were performed by a single vascular specialist in the present study to negate the inter-observer bias. However, ABI testing can be easily performed by primary care physicians after minimal training [31], and should be routinely done for HIV patients. If abnormal ABI is found in HIV patients, their cardiovascular and infectious disease risk factors should be managed more aggressively.

\section{Study Limitations}

The results of this study should be interpreted within the scope and limitations of its design. Ours is a single center study with data collected specific to our institution. Even though, there was a large volume of sex-matched control group, the sample size in the HIV group was small. Finally, the claudication score and ABI results were not confirmed with arterial ultrasound.

\section{Conclusions}

The prevalence of PAD is higher in HIV-infected patients as compared to sex-matched non-HIV controls. Clinicians should routinely screen for PAD in HIV patients using simple tool like ABI measurement. Apart from correlation with cardiovascular risk factors, strong association between lower CD4 cell count and abnormal ABI exists. This warrants more aggressive approach in managing cardiovascular and infectious markers in HIV-infected patients with abnormal ABI.

\section{References}

1. Manfredi R (2004) HIV infection and advanced age emerging epidemiological, clinical, and management issues. Ageing Res Rev 3: 31-54.

2. van Sighem Al, Gras LA, Reiss P, Brinkman K, de Wolf F, et al. (2010) Life expectancy of recently diagnosed asymptomatic HIV-infected patients approaches that of uninfected individuals. AIDS 24: 1527-1535.

3. Monsuez JJ, Charniot JC, Escaut L, Teicher E, Wyplosz B, et al. (2009) HIVassociated vascular diseases: structural and functional changes, clinical implications. Int J Cardiol 133: 293-306. 
Citation: Gupta N, Bajaj S, Shah P, Parikh R, Gupta I, et al. (2013) The Prevalence of Peripheral Arterial Disease in HIV Patients. J Vasc Med Surg 1: 118 doi: 10.4172/2329-6925.1000118

4. Carr A, Samaras K, Thorisdottir A, Kaufmann GR, Chisholm DJ, et al. (1999) Diagnosis, prediction and natural course of HIV-1 protease-inhibitor-associated lipodystrophy, hyperlipidaemia, and diabetes mellitus: a cohort study. Lancet 353: 2093-2099.

5. Periard D, Telenti A, Sudre P, Cheseaux JJ, Halfon P, et al. (1999) Atherogenic dyslipidemia in HIV-infected individuals treated with protease inhibitors. The Swiss HIV Cohort Study. Circulation 100: 700-705.

6. Paraskevas $\mathrm{KI}$, Mikhailidis DP (2008) C-reactive protein (CRP): more than just an innocent bystander? Curr Med Res Opin 24: 75-78.

7. Athyros VG, Kakafika Al, Karagiannis A, Mikhailidis DP (2008) Do we need to consider inflammatory markers when we treat atherosclerotic disease? Atherosclerosis 200: 1-12.

8. Hsue PY, Lo JC, Franklin A, Bolger AF, Martin JN, et al. (2004) Progression of atherosclerosis as assessed by carotid intima-media thickness in patients with HIV infection. Circulation 109: 1603-1608.

9. Charakida M, Donald AE, Green H, Storry C, Clapson M, et al. (2005) Early structural and functional changes of the vasculature in HIV-infected children: impact of disease and antiretroviral therapy. Circulation 112: 103-109.

10. Mangili A, Gerrior J, Tang AM, O'Leary DH, Polak JK, et al. (2006) Risk of cardiovascular disease in a cohort of HIV-infected adults: a study using carotid intima-media thickness and coronary artery calcium score. Clin Infect Dis 43 : $1482-1489$.

11. Topakian R, Nanz S, Rohrbacher B, Koppensteiner R, Aichner FT, et al. (2010) OECROSS Study Group. High prevalence of peripheral arterial disease in patients with acute ischaemic stroke. Cerebrovasc Dis 29: 248-254

12. Periard D, Cavassini M, Taffe P, Chevalley M, Senn L, et al. (2008) High prevalence of peripheral arterial disease in HIV-infected persons. Clin Infect Dis 46: 761-767.

13. Palacios R, Alonso I, Hidalgo A, Aguilar I, Sánchez MA, et al. (2008) Peripheral Arterial Disease in HIV Patients Older than 50 Years of Age. AIDS Res Hum Retroviruses 24: 1-4

14. Bernal E, Masia M, Padilla S, Hernández I, Gutiérrez F (2008) Low prevalence of peripheral arterial disease in HIV-infected patients with multiple cardiovascular risk factors. J Acquir Immune Defic Syndr 471: 126-127.

15. Sharma A, Holman S, Pitts R, Minkoff HL, Dehovitz JA, et al. (2007) Periphera arterial disease in HIV-infected and uninfected women. HIV Med 8: 555-560.

16. Gutierrez F, Bernal E, Padilla S, Hernández I, Masiá M (2008) Relationship between ankle-brachial index and carotid intima-media thickness in HIVinfected patients. AIDS 22: 1369-1371.

17. Olalla J, Salas D, Del Arco A, De la Torre J, Prada J, et al. (2009) Ankle-branch index and HIV: the role of antiretrovirals. HIV Med 10: 1-5.
18. Qaqa AY, DeBari VA, Isbitan A, Mohammad N Sison R, et al. (2011) The role of post-exercise measurements in the diagnosis of peripheral arterial disease in HIV-infected patients. Angiology 62: 10-14.

19. Olalla J, Salas D, de la Torre J, Del Arco A, Prada JL, et al. (2009) Anklebrachial index in HIV infection. AIDS Res Ther 6: 6 .

20. Leng GC, Fowkes FG (1992) The Edinburgh Claudication Questionnaire: an improved version of the WHO/Rose Questionnaire for use in epidemiological surveys. J Clin Epidemiol 45: 1101-1109.

21. Carter SA (1972) Respons of ankle systolic pressure to leg exercise in mild or questionable arterial disease. N Engl J Med 287: 578-582.

22. Hirsch AT, Haskal ZJ, Hertzer NR (2006) ACC/AHA 2005 practice guidlines fo the management of patients with peripheral arterial disease. Circulation 113 463-654.

23. Expert Panel on Detection, Evaluation, and Treatment of High Blood Cholesterol in Adults (2001) Executive summary of the third report of the national cholesterol education program (NCEP) expert panel on detection, evaluation, and treatment of high blood cholesterol in adults (Adult Treatment Panel III). JAMA 285: 2486-2497.

24. Alberti KG, Zimmet P, Shaw J (2006) Metabolic syndrome-a new world-wide definition. A consensus statement from the International Diabetes Federation. Diabet Med 23: 469-480.

25. Stein R, Hriljac I, Halperin JL, Gustavson SM, Teodorescu V, et al. (2006) Limitation of the resting ankle-brachial index in symptomatic patients with peripheral arterial disease. Vasc Med 11: 29-33.

26. Zheng ZJ, Rosamond WD, Chambless LE, Nieto FJ, Barnes RW, et al. (2005) Lower extremity arterial disease assessed by ankle-brachial index in a middleaged population of African American and Whites. The Atherosclerosis Risk in Communities (ARIC) Study. Am J prev Med 29: 42-49.

27. Murabito JM, Evans JC, Nieto K, Larson MG, Levy D, et al. (2002) Prevalence and clinical correlates of peripheral arterial disease in the Framingham Offspring Study. Am Heart J 143: 961-965.

28. Ankle Brachial Index Collaboration, Fowkes FG, Murray GD, Butcher I, Heald CL, et al. (2008) Ankle brachial index combined with Framingham Risk Score to predict cardiovascular events and mortality: a meta-analysis. JAMA 300: 197-208.

29. Hsue PY, Hunt PW, Schnell A, Kalapus SC, Hoh R, et al. (2009) Role of vira replication, antiretroviral therapy, and immunodeficiency in HIV-associated atherosclerosis. AIDS 23: 1059-1067.

30. Vogt MT, Cauley JA, Newman AB, Kuller LH, Hulley SB (1993) Decreased ankle/ arm blood pressure index and mortality in elderly women. JAMA 270: 465-469.

31. Hayoz D, Bounameaux H, Canova CR (2005) Swiss Atherothrombosis Survey: a field report on the occurrence of symptomatic and asymptomatic periphera arterial disease. J Intern Med 258: 238-243. 